\title{
CCK receptor antagonism by loxiglumide and gall bladder contractions in response to cholecystokinin, sham feeding and ordinary feeding in man
}

\author{
J W KONTUREK, S J KONTUREK, A KUREK, J BOGDAL, J OLEKSY, \\ AND L ROVATI
}

From the Institute of Physiology, Academy of Medicine, Krakow, Poland and Rotta Research Laboratorium, Milano, Italy

SUMmaRy The postprandial contractions of the gall bladder result from the interaction of neurohormonal factors but their relative contribution is unknown. This study was designed to determine the role of cholecystokinin (CCK) in gall bladder contractions using a highly selective and potent CCK-receptor antagonist, CR-1505 (loxiglumide) in healthy men either infused with exogenous CCK in graded doses $(1 \cdot 56-50 \mathrm{pmol} / \mathrm{kg} / \mathrm{h})$ or subjected to modified sham feeding (MSF) and ordinary feeding tests. The gall bladder volume measured by real time ultrasonography showed dose dependent decrease in the gall bladder volume in 10 subjects when CCK8 was infused iv in graded doses reaching about $15 \%$ at $1.56 \mathrm{pmol} / \mathrm{kg} / \mathrm{h}$ and $91 \%$ at $50 \mathrm{pmol} / \mathrm{kg} / \mathrm{h}$. Close correlation between the decrease in gall bladder volume and the dosage of CCK or the increments in plasma CCK-bioactivity was observed. After pretreatment with loxiglumide, CCK resulted in similar increments in plasma CCK-bioactivity but failed to affect the gall bladder volume at CCK doses up to $6 \cdot 25 \mathrm{pmol} / \mathrm{kg} / \mathrm{h}$ and caused only $53 \%$ reduction at $50 \mathrm{pmol} / \mathrm{kg} / \mathrm{h}$. Modified sham feeding and real feeding reduced the volume of gall bladder by $20 \%$ and $70 \%$, respectively and loxiglumide decreased these values to $15 \%$ and $30 \%$, respectively. This study provides evidence that loxiglumide is highly potent and selective CCK antagonist and that endogenous CCK plays an important role both in the postprandial contractions of gall bladder.

Since 1928 when Ivy and Oldberg' discovered that cholecystokinin (CCK), present in the extracts of canine intestinal mucosa, stimulated the contractions of gall bladder, numerous studies have provided evidence that CCK is the major factor responsible for the gall bladder emptying in animals and in men under various physiological conditions. ${ }^{2}$

In recent years, the non-invasive techniques such as real time ultrasonography have been used to quantify the gall bladder emptying ${ }^{34}$ and sensitive assays have been developed ${ }^{5 \rightarrow 7}$ to measure physiological alterations in plasma concentrations of CCK. With these methods, the dynamics of gall bladder emptying have been characterised and strong evidence supporting a causal relationship between plasma CCK concentrations and gall bladder con-

Address for correspondence: Prof Dr S J Konturek, Institute of Physiology MA, 31-531 Krakow, ul Grzegorzecka 16, Poland.

Accepted for publication 4 January 1989. tractions has been shown. ${ }^{4}$ As originally proposed by Ivy and Oldberg' postprandial gall bladder emptying occurs mainly as the result of CCK-induced gall bladder contractions.

Gall bladder contractions also occur, however, during vagal cholinergic stimulation ${ }^{84}$ and after feeding when the plasma CCK concentrations either remain low or are only moderately raised. ${ }^{9}$ The mechanism of these contractions and the possible involvement of CCK in postprandial conditions remains uncertain. The assessment of the contribution of CCK has been now possible because of recent description of highly specific and potent CCKreceptor antagonists ${ }^{1011}$ which allow the gall bladder contractions to be measured in the absence of the effect of CCK.

This study was undertaken to clarify the role of CCK in the gall bladder contractions during the interdigestive period, after administration of 
exogenous CCK and after sham feeding or ordinary feeding using CR 1505 (loxiglumide), a potent and highly effective CCK-receptor antagonist."

\section{Methods}

SUBJECTS

Studies were carried out on 20 young healthy male subjects (mean age 24 years, range 18-30; mean weight $72 \mathrm{~kg}$, range 62-78) divided into two groups, $A$ and B. Group A subjects underwent basal-CCK8 infusion tests without or with pretreatment with loxiglumide, while group B subjects were used in modified sham feeding (MSF-real feeding tests) without or with pretreatment with loxiglumide. The study was approved by Human Research Review Committee and informed consent was obtained from each subject.

All experiments were carried out after an overnight fast. In basal-CCK infusion tests, placebo tablet or loxiglumide tablet $(800 \mathrm{mg})$ were ingested and then 30 minutes later the gall bladder volumes were measured by two investigators unaware of the treatment by real time ultrasonography ${ }^{348}$ every 10 minutes (using Ultrasound Scanner, EUB-240, Hitachi, Japan). Blood samples were drawn at the same time for measurements of plasma CCK, gastrin and pancreatic polypeptide (PP). After a basal 30 minute period, CCK8 (gift from Professor $\mathrm{N}$ Yanaihara, Shizuoka, Japan) dissolved in $1 \%$ of human albumin was infused iv in gradually increasing doses $(1 \cdot 56-50 \cdot 0 \mathrm{pmol} / \mathrm{kg} / \mathrm{h})$, each dose being administered for 30 minutes and then doubled. The measurements of gall bladder volumes and withdrawals of blood samples for plasma hormone assays were continued at 10 minute intervals with each dose levels of CCK8 infusion. Mean values of gall bladder volume and plasma hormones data under basal conditions and at each dose level of CCK8 were calculated from three 10 minute data. These basalCCK8 infusion tests with placebo or loxiglumide were performed at seven to 10 day intervals at random order. Loxiglumide obtained from Rotta Labs, Milano, Italy was used in tablets containing $800 \mathrm{mg}$ of agent. Placebo tablets identical in appearance contained only inert ingredients of cornstarch and microcrystalline cellulose.

In group B subjects, the MSF-real feeding tests were performed. Again, a placebo or loxiglumide tablet $(800 \mathrm{mg})$ was ingested and then 30 minutes later basal gall bladder volumes and venous blood samples for hormone assays were obtained at 15 minute intervals during 60 minute period. Then a double lumen gastroduodenal Dreiling tube with endotracheal cuff was inserted and inflated with $20 \mathrm{ml}$ of air just distally to the pylorus to prevent any escape of gastric acid into the duodenum and release of endogenous hormones as described. ${ }^{12}$ The volumes of gastric aspirates were recorded, the acidity measured by titration of the samples to $\mathrm{pH} 7 \cdot 0$ and acid outputs expressed in $\mathrm{mmol} / 30 \mathrm{~min}$. Modified sham feeding was performed by the 'chew and spit' technique ${ }^{12}$ for 15 minutes using an appetising meal of $250 \mathrm{~g}$ beef steak, $150 \mathrm{~g}$ French fried potatoes and $250 \mathrm{ml}$ of water as described. Gastric aspiration was continued for a 90 minute period during which real time sonograms of gall bladder and blood samples for plasma hormone assays were obtained every 15 minutes. After the MSF test, the gastroduodenal tube was removed and the test with ordinary feeding started. Subjects ingested during 15 minutes a similar meal as for MSF, except that water was replaced by cream containing $15 \%$ fat and two egg yolks. Gall bladder volumes were measured and blood samples taken at 15 minute intervals during a 120 minute period. The two studies with MSF-real feeding with placebo or with loxiglumide were separated by a period of seven to 10 days in random order.

Venous blood samples, obtained in tests with basal-CCK8 infusion and MSF-real feeding without or with pretreatment with loxiglumide, were collected into chilled tubes containing $500 \mathrm{KIU}$ aprotonin (Trasylol, Bayer FRG) and $0.15 \mathrm{mg}$ ethylene-diamine tetraacetic acid per millilitre of whole blood and centrifuged at $4^{\circ} \mathrm{C}$ for 10 minutes. Cholecystokinin-bioactivity was extracted and concentrated on Sep Pak C18 cartridges (Waters Ass, Milford, Mass, USA) before bioassay. Plasma CCK was measured immediately by bioassay technique using isolated rat pancreatic acini and amylase release as described ${ }^{67}$ The amylase stimulating effect of the extracted plasma samples was related to the amylase-stimulating effect of CCK8 and the data are expressed as equivalent CCK-bioactivity. The presence of loxiglumide in plasma samples did not interfere with CCK bioassay because this nonpeptide agent appears not to be adsorbed nor eluted by ethanol from the SEP-PACK C18 column. This has been checked by adding loxiglumide at concentrations $10^{-8}-10^{-4} \mathrm{M}$ to the plasma samples containing known concentrations of $\mathrm{CCK}$ and by extracting this CCK and subsequent bioassay on rat pancreatic acini. At all concentrations loxiglumide failed to affect the amylase stimulating ability of extracted CCK from the tested plasma. These data have not been included.

Plasma gastrin and polypeptide were measured by specific radioimmunoassays as described. ${ }^{1213}$ The assay systems were sufficiently sensitive to detect $0.5 \mathrm{pM}$ plasma CCK, $1.25 \mathrm{pM}$ plasma gastrin, and $2 \cdot 2$ pM plasma polypeptide.

Results are expressed as the means (SE). Repeated 
measures analysis of variance was used to evaluate significance between the experimental procedures. Differences with $\mathrm{p}<0.05$ were considered significant.

\section{Results}

\section{EFFECTS OF LOXIGLUMIDE ON CCK-INDUCED \\ GALL BLADDER VOLUME AND PLASMA \\ CONCENTRATIONS OF CCK, GASTRIN AND \\ POLYPEPTIDE}

The volume of gall bladder measured by real time ultrasonography in fasted placebo treated subjects of group A was $29.9(2 \cdot 1) \mathrm{ml}$. In separate tests carried out on these subjects for 240 minutes the volume of gall bladder showed periodic individual fluctuations ranging from 23.4 to $36.5 \mathrm{ml}$ but on average the volume was well sustained throughout the test. Intravenous infusion of graded doses of CCK8 caused a dose dependent reduction in the gall bladder volume. The significant reduction (by about $15 \%$ ) was observed at a dose of $1.56 \mathrm{pmol} / \mathrm{kg} / \mathrm{h}$ and about $91 \%$ reduction was recorded at a dose of $50 \mathrm{pmol} /$ $\mathrm{kg} / \mathrm{h}$. The calculated dose of CCK causing about $50 \%$ reduction in the gall bladder volume was $7.8(2.5)$ $\mathrm{pmol} / \mathrm{kg} / \mathrm{h}$ (Fig. 1).

After oral administration of loxiglumide $(800 \mathrm{mg})$,

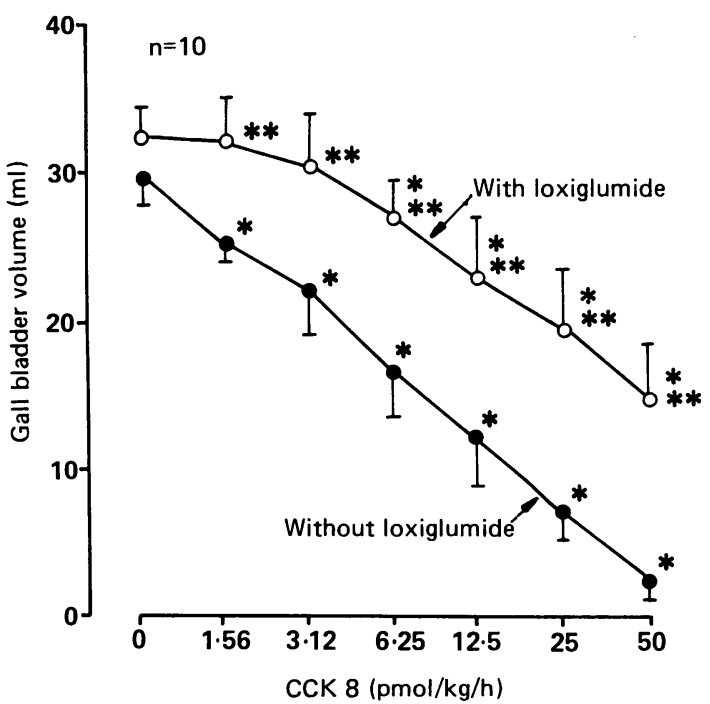

Fig. 1 Gall bladder volume in group A subjects before and after infusion of graded doses of CCK8 in tests with placebo (without loxiglumide) and with loxiglumide pretreatment. Means (SE) of 10 determinations in 10 tested subjects. Each value is the mean of three measurements performed during 30 min period before $C C K$ and at each dose of $C C K$ infused. *Indicates significant $(p<0 \cdot 05)$ decrease below the value obtained under basal state. ${ }^{*}$ Indicate significant increase above the value obtained in tests without loxiglumide.
Table 1 Plasma concentrations of CCK-bioactivity and of gastrin and polypeptide immunoreactivity in group $A$ subjects pretreated with placebo or loxiglumide and infused with graded doses of CCK. Means (SE) of 10 determinations in 10 subjects

\begin{tabular}{lrll}
\hline & $C C K p M$ & Gastrin $p M$ & PP $M M$ \\
\hline Placebo & & & \\
Basal & $1 \cdot 2(0 \cdot 3)$ & $22 \cdot 5(3 \cdot 6)$ & $22 \cdot 4(3 \cdot 2)$ \\
CCK $1 \cdot 56 \mathrm{pmol} / \mathrm{kg} / \mathrm{h}$ & $2 \cdot 3(0 \cdot 5)$ & $18 \cdot 6(3 \cdot 2)$ & $26 \cdot 1(3 \cdot 9)$ \\
$3 \cdot 12 \mathrm{pmol} / \mathrm{kg} / \mathrm{h}$ & $4 \cdot 0(0 \cdot 7)$ & $27 \cdot 5(4 \cdot 1)$ & $32 \cdot 7(4 \cdot 2)$ \\
$6 \cdot 25 \mathrm{pmol} / \mathrm{kg} / \mathrm{h}$ & $6 \cdot 9(1 \cdot 6)$ & $27 \cdot 1(2 \cdot 8)$ & $39 \cdot 9(5 \cdot 2)$ \\
$12 \cdot 5 \mathrm{pmol} / \mathrm{kg} / \mathrm{h}$ & $9 \cdot 0(3 \cdot 4)$ & $34 \cdot 2(6 \cdot 2)$ & $46 \cdot 6(7 \cdot 6)$ \\
$25 \cdot 0 \mathrm{pmol} / \mathrm{kg} / \mathrm{h}$ & $13 \cdot 4(5 \cdot 9)$ & $26 \cdot 2(3 \cdot 1)$ & $52 \cdot 4(9 \cdot 8)$ \\
$50 \cdot 0 \mathrm{pmol} / \mathrm{kg} / \mathrm{h}$ & $21 \cdot 5(7 \cdot 4)$ & $23 \cdot 8(4 \cdot 2)$ & $75 \cdot 8(12 \cdot 4)$ \\
Loxiglumide & & & \\
Basal & $1 \cdot 1(0 \cdot 6)$ & $21 \cdot 9(3 \cdot 8)$ & $20 \cdot 5(2 \cdot 8)$ \\
CCK $1 \cdot 56 \mathrm{pmol} / \mathrm{kg} / \mathrm{h}$ & $2 \cdot 6(0 \cdot 4)$ & $23 \cdot 4(3 \cdot 6)$ & $22 \cdot 3(1 \cdot 9)$ \\
$3 \cdot 12 \mathrm{pmol} / \mathrm{kg} / \mathrm{h}$ & $3 \cdot 9(0 \cdot 8)$ & $25 \cdot 1(2 \cdot 9)$ & $21 \cdot 7(2 \cdot 2)$ \\
$6 \cdot 25 \mathrm{pmol} / \mathrm{kg} / \mathrm{h}$ & $5 \cdot 2(1 \cdot 4)$ & $31 \cdot 0(4 \cdot 2)$ & $24 \cdot 6(3 \cdot 2)$ \\
$12 \cdot 5 \mathrm{pmol} / \mathrm{kg} / \mathrm{h}$ & $9 \cdot 7(2 \cdot 1)$ & $30 \cdot 0(2 \cdot 7)$ & $30 \cdot 7(2 \cdot 8)^{*}$ \\
$25 \cdot 0 \mathrm{pmol} / \mathrm{kg} / \mathrm{h}$ & $17 \cdot 6(3 \cdot 4)$ & $26 \cdot 3(1 \cdot 8)$ & $34 \cdot 8(2 \cdot 9)^{*}$ \\
$50 \cdot 0 \mathrm{pmol} / \mathrm{kg} / \mathrm{h}$ & $22 \cdot 8(5 \cdot 2)$ & $24 \cdot 2(2 \cdot 2)$ & $38 \cdot 6(4 \cdot 2)^{*}$ \\
\hline
\end{tabular}

*Significant $(\mathrm{p}<0.05)$ decrease below the value obtained in tests with placebo.

the basal volume of gall bladder tended to increase but this did not reach statistical significance in this group of subjects. Infusion of CCK in loxiglumide treated subjects failed to affect significantly this volume at a dose from 1.56 to $6.25 \mathrm{pmol} / \mathrm{kg} / \mathrm{h}$. With further increase in the dosage of CCK8, a gradual reduction in the gall bladder volume was found reaching at $50 \mathrm{pmol} / \mathrm{kg} / \mathrm{h}$ about $53 \%$ of the initial value. The calculated dose of CCK that reduced by $50 \%$ the gall bladder volume in loxiglumide treated subjects was about $46 \cdot 2(5 \cdot 6) \mathrm{pmol} / \mathrm{kg} / \mathrm{h}$. The difference in the gall bladder volume recorded in tests with placebo and loxiglumide was significant at all doses of CCK8 used.

The plasma hormone concentrations (CCK, gastrin and PP) in tests with infusion of graded doses of CCK8 without or with loxiglumide are shown in Table 1. Basal value of CCK-bioactivity in placebotreated subjects was $1.2(0.4) \mathrm{pM}$. Infusion of 1.56 , $3 \cdot 12,6 \cdot 25,12 \cdot 5,25$, and $50 \mathrm{pmol} / \mathrm{kg} / \mathrm{h}$ resulted in the increment (over basal) of CCK-bioactivity by about $1 \cdot 0(0 \cdot 3), 1 \cdot 8(0 \cdot 4), 4 \cdot 7(1 \cdot 2), 7 \cdot 8(2 \cdot 3), 12 \cdot 2(4 \cdot 2)$, and $20 \cdot 3(5 \cdot 8) \mathrm{pM}$. These increments in plasma CCK in tests with placebo were not significantly different from those obtained with pretreatment with loxiglumide. The relations between plasma CCK concentrations and the gall bladder volume recorded during infusion of graded doses of CCK in tests with placebo and loxiglumide are shown in Figure 2. All increments in plasma CCK concentrations occurring during CCK infusion resulted in a significant reduction in the gall bladder volume. About 50\% 


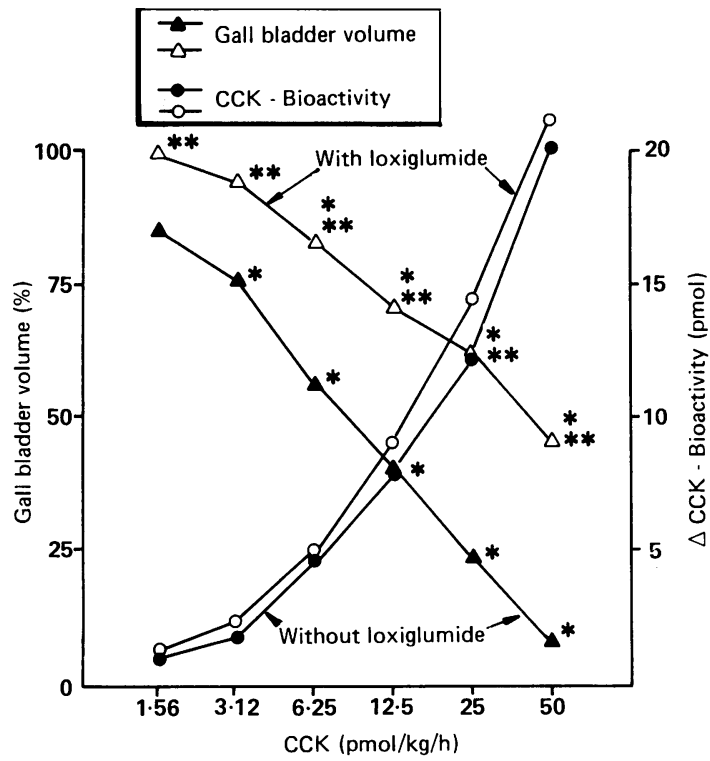

Fig. 2 Relationship between the gall bladder volume and the increments in plasma $C C K$-bioactivity after iv infusion of graded doses of CCK8 in subjects treated with placebo or loxiglumide as in Figure 1. *Indicates significant change as compared to basal value. ${ }^{* *}$ Indicate significant increase above the value obtained in tests with placebo.

reduction in the volume was observed with an increment in plasma CCK by about $7.9 \mathrm{pM}$. After the ingestion of loxiglumide, almost three times higher plasma CCK concentrations (about 19.8 pM) was required to achieve this $50 \%$ reduction in the gall bladder volume.

Plasma gastrin was unaffected by the infusion of CCK8 at any dose used in tests without or with loxiglumide. Plasma concentrations of PP showed a progressive increase with increasing doses of CCK8 from the basal value of $22 \cdot 4(3 \cdot 2) \mathrm{pM}$ to $75 \cdot 8(12) \mathrm{pM}$ attained at the highest dose of CCK $8(50 \mathrm{pmol} / \mathrm{kg} / \mathrm{h})$. In tests with loxiglumide basal plasma PP concentrations were unchanged but after infusion of CCK they were significantly lower than those recorded in placebo group (Table 1).

EFFECTS OF LOXIGLUMIDE ON THE GALL BLADDER VOLUME AND PLASMA HORMONE CONCENTRATIONSIN TESTS WITH MSF AND REAL FEEDING

Sham feeding an appetising meal in placebo treated group B subjects resulted in almost immediate and significant decrease in the gall bladder volume by about $20 \%$ of the initial volume. This reduction was observed for about 60 minutes but then, after 90 minutes, the volume returned to the initial value.

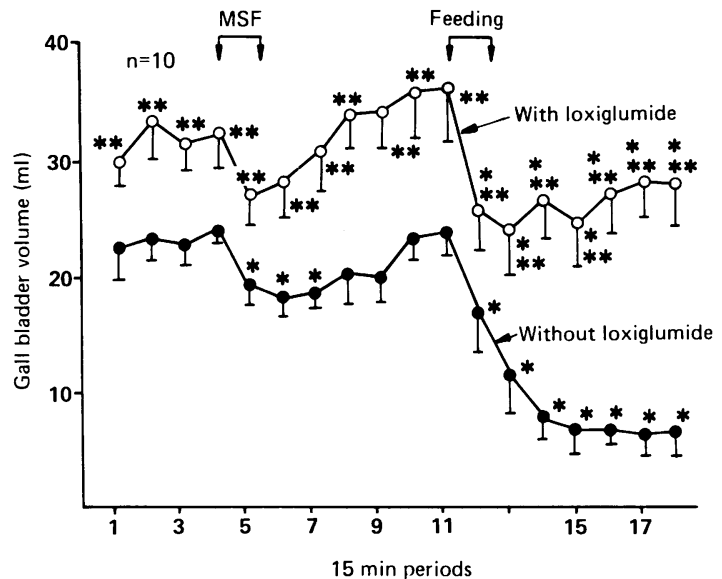

Fig. 3 Gall bladder volume in tests with MSF and ordinary feeding in group B subjects pretreated with placebo (without loxiglumide) or with loxiglumide. Mean (SE) of 10 determinations. *Indicates significant decrease below the value obtained under basal state. ${ }^{* *}$ Indicate significant increase above the value obtained in tests with placebo (without loxiglumide).

After subsequent real feeding, the volume of gall bladder was reduced by about $50 \%$ in the first 15 minutes and then the reduction was continued until the volume diminished by about $70 \%$ (Fig. 3). After pretreatment with loxiglumide $(800 \mathrm{mg} \mathrm{po})$ basal gall bladder volume was significantly greater and the reduction in this volume caused by MSF was smaller (about 15\%) and not significant as compared with that in tests without loxiglumide. Modified sham feeding resulted in a marked increase in gastric acid secretion from basal $0.87(0.21) \mathrm{mmol} / 15$ to a peak $2.73(0.31) \mathrm{mmol} / 15$ and these effects were not significantly altered by the pretreatment with loxiglumide.

In tests with real feeding in loxiglumide treated subjects, the reduction in the gall bladder volume reached about $30 \%$ in the first 15 minute period but then failed to show any further reduction for the remaining postprandial period.

Plasma CCK-bioactivity as well as plasma gastrin concentrations after MSF were unaffected both in tests without and with loxiglumide (Table 2). Plasma polypeptide concentration rose from basal of 28.6 (3.7) $\mathrm{pM}$ to the peak $42.4(5.5) \mathrm{pM}$ during the 15 minutes of MSF but then quickly returned to the previous level. Loxiglumide did not significantly affect this increment in plasma polypeptide.

After real feeding, plasma CCK bioactivity showed a prolonged rise from basal value of $1 \cdot 4(0 \cdot 5)$ pM to the peak of $5 \cdot 1(2 \cdot 1)$ pM occurring about 60 minutes after feeding. Pretreatment with loxiglumide 
Table 2 Plasma CCK-bioactivity and gastrin-and PPimmunoreactivity in group $B$ subjects pretreated with placebo or loxiglumide before and after MSF and ordinary feeding. Means of 10 determinations in 10 subjects.

\begin{tabular}{|c|c|c|c|}
\hline & $C C K p M$ & Gastrin $p M$ & $P P p M$ \\
\hline \multicolumn{4}{|l|}{ Placebo } \\
\hline Basal & $1.4(0.5)$ & $18 \cdot 6(3 \cdot 7)$ & $28 \cdot 6(3 \cdot 7)$ \\
\hline MSF & $2 \cdot 2(0 \cdot 6)$ & $27 \cdot 3(6 \cdot 8)$ & $42.4(5.0)^{*}$ \\
\hline Feeding & $5 \cdot 1(2 \cdot 1)^{*}$ & $62 \cdot 4(7 \cdot 8)^{*}$ & $170.4(28.2)^{*}$ \\
\hline \multicolumn{4}{|c|}{ Loxiglumide } \\
\hline Basal & $1 \cdot 1(0 \cdot 3)$ & $22 \cdot 1(3 \cdot())$ & $20 \cdot 3(4 \cdot 1)$ \\
\hline MSF & $1 \cdot 9(0 \cdot 3)$ & $29 \cdot 3(4 \cdot 5)$ & $37 \cdot 6(5 \cdot 2)^{*}$ \\
\hline Feeding & $6.0(1 \cdot 7)^{*}$ & $84 \cdot 3(12 \cdot 4)^{*}$ & $98 \cdot 2(18 \cdot 3)^{* *}$ \\
\hline
\end{tabular}

*Significant $(\mathrm{p}<0 \cdot 05)$ increase above basal value; **Significant $(p<0 \cdot 05)$ decrease below the value obtained with placebo.

failed to affect the plasma CCK response to a meal. Also plasma gastrin response (an increment from basal $18.6(3.7) \mathrm{pM}$ to a peak of $62.4(7.8) \mathrm{pM})$ to a meal was not significantly affected by loxiglumide. Plasma polypeptide concentration after feeding rose to a peak of $170(28) \mathrm{pM})$ and this was reduced by about $42 \%$ in tests with loxiglumide.

No discomfort or abnormal findings were recorded in subjects treated with loxiglumide.

\section{Discussion}

This study provides evidence that CR-1505 is a potent CCK antagonist and that endogenous CCK has tonic action on the gall bladder under basal state and is the major factor responsible for the postprandial gall bladder contractions in man.

Previous studies ${ }^{349}$ using real time ultrasonography of the gall bladder showed that this is an easy and reliable method to quantify gall bladder contractions and that the assessment of the reduction in gall bladder volume may serve as a highly sensitive method of detection of increments in plasma concentrations of CCK. ${ }^{+}$The threshold for stimulating of gall bladder contractions was the increment in plasma immunoreactive CCK by $1.3 \mathrm{pM}$ when a dose of 0.8 $\mathrm{pmol} / \mathrm{kg} / \mathrm{h} \mathrm{CCK}$ was administered. ${ }^{4}$ A highly significant correlation was found between the decreases in gall bladder volume and the dosage of infused CCK or the increment in plasma CCK concentrations. Our study fully confirmed the usefulness of serial ultrasonography in detecting minute alterations in the dosage of CCK or in the plasma concentrations of this hormone. Cholecystokinin at a dose of $1.56 \mathrm{pmol} /$ $\mathrm{kg} / \mathrm{h}$, that raised plasma CCK bioactivity by about 1.0 $\mathrm{pM}$, caused a significant reduction (by about $15 \%$ ) in gall bladder volume. Further increase in the dosage of infused CCK or in the plasma CCK-bioactivity resulted in a gradual decrease in gall bladder volume reaching at a dose of $50 \mathrm{pmol} / \mathrm{kg} / \mathrm{h}$ of CCK about $91 \%$ of the initial value.

The major finding of this study is that oral pretreatment with loxiglumide abolished the gall bladder motor responses to CCK at lower doses and greatly reduced those at higher doses of CCK. In loxiglumide treated subjects the threshold dose of exogenous CCK, that caused a significant diminution in the gall bladder volume, was $6.25 \mathrm{pmol} / \mathrm{kg} / \mathrm{h}$ - that is, about four times higher than in tests without loxiglumide. The dose of infused CCK and the increment in plasma CCK-bioactivity producing $50 \%$ reduction in gall bladder volume were four to six times higher in loxiglumide treated subjects than in untreated placebo controls. This indicates that loxiglumide greatly reduced the sensitivity of CCK receptors in the gall bladder muscle to the agonist. As loxiglumide reduced both the maximal gall bladder response to CCK and significantly increased the dose of the agonist producing $50 \%$ reduction in gall bladder volume, loxiglumide functions in vivo, unlike in vitro, ${ }^{11}$ as mixed type CCK-receptor antagonist .

It is of interest that in dogs, proglumide used in a massive dose $(300 \mathrm{mg} / \mathrm{kg} / \mathrm{h})$ not only abolished the gall bladder contraction caused by intra-duodenal Lipomul, a potent releaser of endogenous CCK but also increased the basal gall bladder volume. ${ }^{14}$ Although this effect has been attributed to increased hepatic bile production by proglumide, it could also result from the removal by this CCK-antagonist of basal CCK background stimulation of the gall bladder motor 'tone'. Proglumide has relatively low potency as CCK antagonist, while loxiglumide, a proglumide analogue obtained by altering the structure of dialkyl amide and by addition of benzoyl moiety" 1" exhibits over 1000 times higher CCK antagonistic activity than proglumide. It appears to be active after parenteral and oral administration and because of good tolerance and no toxicity ${ }^{15}$ it has been considered for diagnostic and therapeutic uses in disorders of the motility of biliary tract. As with proglumide in animals, ${ }^{14}$ loxiglumide in our subjects increased the volume of the unstimulated gall bladder suggesting that circulating $\mathrm{CCK}$ in fasted humans displays a tonic influence on the gall bladder smooth muscle.

Our finding that loxiglumide is a highly effective CCK antagonist prompted our subsequent studies designed to determine the role of CCK in gall bladder contractions elicited by cephalic-vagal stimulation and by ordinary feeding. Cephalic vagal stimulation was induced by the 'chew and spit' technique, which is known and confirmed by this study to evoke a potent gastric acid secretion. ${ }^{12}$ Such modified sham feeding (MSF) was found previously to induce about $30 \%$ reduction in the gall bladder volume" but in that 
report gastric acid was not aspirated so that it could enter the duodenum and release endogenous CCK.? This CCK release, even undetected by radioimmunoassay, could enhance the vagally induced contraction of gall bladder. According to our data, modified sham feeding does reduce significantly the gall bladder volume even in subjects with aspirated gastric acid but the reduction is relatively smaller (about $20 \%$ ) than reported before" possibly because of the aspiration of gastric acid and the prevention of release of CCK by endogenous duodenal acidification.

The mechanism of the small but significant reduction by modified sham feeding in the gall bladder volume is unclear but previous study of Hopman et $a l^{\prime \prime}$ suggested the involvement of vagalcholinergic component because atropine completely abolished the modified sham feeding induced decrease in the gall bladder volume. In our subjects, the pretreatment with loxiglumide increased basal gall bladder volume and also attenuated the decrease of this volume caused by modified sham feeding. This diminution of modified sham feeding induced decrease in the gall bladder volume could be explained by the reduction by loxiglumide in the effectiveness of vagal-cholinergic input because of the removal of the tonic action of endogenous CCK on the gall bladder. This is supported by experimental finding showing that acetylcholine and CCK interacts at smooth muscle cells so that the response to a combination of agonists exceeds the sum of the two individual effects and the blockade of receptors for one agonist diminishes the activity of the other agonist. ${ }^{16} 17$

This study also attempted to determine the role of CCK in the postprandial contraction of gall bladder. Feeding of fat and protein rich meal resulted in about $70 \%$ reduction in gall bladder. The blockade of CCK receptors by loxiglumide was followed by only $30 \%$ reduction in gall bladder volume. This indicates that CCK is the major but not the only factor responsible for the postprandial decrease in gall bladder volume. This is supported by the increment in plasma CCK bioactivity by $3.7 \mathrm{pM}$ but such CCK increment alone such as induced by exogenous CCK should cause much smaller decrease in the gall bladder volume than that observed postprandially. This indicates that in addition to CCK, other factors, particularly vagalcholinergic stimulation elicited by neural reflexes activated by feeding, may contribute to the postprandial decrease in the gall bladder volume. ${ }^{2 \times 4}$

Cholecystokinin infused exogenously or released endogenously is known to stimulate the release of polypeptide. ${ }^{18}$ Indeed, graded doses of CCK produced gradual increase in plasma polypeptide concentrations. This effect appears to be mediated by
CCK receptors as loxiglumide was highly effective in the reduction in plasma polypeptide response to infused CCK. Similarly, plasma polypeptide rose after feeding possibly due to the action of endogenous CCK but the postprandial increment in plasma polypeptide was several times greater than that achieved with exogenous CCK producing equal rate increase in plasma CCK and was only partly attenuated by loxiglumide. This could be interpreted that polypeptide-releasing cells are sensitive to a variety of other than CCK stimulants, particularly to vagal-cholinergic input, and that CCK is only a minor factor in the postprandial release of polypeptide. As polypeptide was reported to relax the gall bladder" it is possible that highly raised plasma polypeptide after a meal in both loxiglumide treated and untreated subjects could counteract, at least in part, the effects of endogenous CCK and other stimulants of the gall bladder motility. This could contribute to relatively smaller effect of endogenous stimulants on gall bladder contraction in the postprandial state as compared with that induced by exogenous hormone when plasma increments in polypeptide concentrations were less marked.

This study was supported in part by research grant CPBP - 06.03.3.6.

\section{References}

1 Ivy AC, Oldberg E. A hormone mechanism for gallbladder contraction and evacuation. Am J Physiol 1928; 86: 599-613.

2 Ryan JP. Motility of the gallbladder and biliary tree. In: Johnson LR, ed. Physiology of the gastrointestinal tract. New York: Raven Press, 1987: 695-721.

3 Everson GT, Braverman DZ, Johnson ML, Kern F Jr. Critical evaluation of real-time ultrasonography for the study of gallbladder volume and contraction. (Gastroenterology 1980; 79: 40-6.

4 Hopman WPM, Kersten PJSM, Janssen JBMJ, Rosenbusch G, Lamers CBHW. Effect of graded physiological doses of cholecystokinin on gallbladder contraction measured by ultrasonography. Gastroenterology 1985; 89: 1242-7.

5 Janssen JBMJ, Lamers CBHW. Radioimmunoassay of cholecystokinin in human tissue and plasma. Clin Chim Acta 1983; 131: 305-9.

6 Liddle RA. Goldfine ID, Rosen MS, Taplitz RA, Williams JA. Cholecystokinin bioactivity in human plasma: molecular forms, responses to feeding, and relationship to gallbladder contraction. J Clin Invest 1985; 75: 1144-.52.

7 Williams JA, Korc M, Dormer RL. Action of secretagogues on a new preparation of functionally intact, isolated pancreatic acini. Am J Physiol 1978; 4: 517-24.

8 Fisher RS, Rock E, Malmud LS. Gallbladder emptying response to sham feeding in humans. Gastroenterology 1986; 90: 1854-7. 
9 Hopman WPM, Jansen JBMJ, Rosenbusch G, Lamers CBHW. Cephalic stimulation of gallbladder contraction in humans: role of cholecystokinin and the cholinergic system. Digestion 1987; 38: 197-203.

10 Makovec F, Bani M, Christe R, Revel L, Rovati LA. Differentiation of control and peripheral cholecystokinin receptors by new glutaramic derivatives with cholecystokinin-antagonistic activity. Arzneim Forsch 1986; 36: 98-102.

11 Sentikar I, Bani M, Cereda R, Christe R, Makovec F, Pacini A, Revel Z. Anticholecystokinin activities of loxiglumide. Arzneim Forsch 1987; 37: 1168-71.

12 Konturek SJ, Kwiecien N, Obtulowicz W, et al. Cephalic phase of gastric secretion in healthy subjects and duodenal ulcer patients. Role of vagal innervation. Gut 1979; 20: 875-81.

13 Konturek SJ, Kwiecien N, Obtulowicz W. Vagal cholinergic control of gastric alkaline secretion in normal subjects and duodenal ulcer patients. Gut 1987 ; 28: $739-44$.

14 Shiratori K, Watanabe S, Chey WY, Lec KY, Chang
T-M. Endogenous cholecystokinin derives gallbladder emptying in dogs. Am J Physiol 1986; 251: 553-8.

15 Rovati LA. Views on possible therapeutic use of gastrin and cholecystokinin antagonists. In: Bali JP, Martinez J, eds. Gastrin and cholecystokinin. Amsterdam: Elsevier, 1987: 225-34.

16 Fosel S, Sewing DF. Enhancement of electrically stimulated guinea pig gallbladder contraction by subthreshold concentrations of gastrointestinal hormones in vitro. Experientia 1978; 24: 205-6.

17 Bitar KN, Makhouf GM. Receptors on smooth muscle cells: characterization by contraction and specific antagonists. Am J Physiol 1982; 242: 400-7.

18 Konturek SJ, Tasler J, Cieszkowski M, Szewczyk K, Hladij M. Effect of cholecystokinin receptor antagonist on pancreatic responses to exogenous gastric and cholecystokinin and to meal stimuli. Gastroenterology 1988; 94: 1014-23.

19 Adrian TE, Mitchenere P, Sagor G, Bloom SR. Effect of pancreatic polypeptide on gallbladder pressure and hepatic bile flow. Am J Physiol 1982; 243: 204-7. 